\title{
Assessment of Sirwan River Water Quality from Downstream of Darbandikhan Dam to Kalar District, Kurdistan Region, Iraq
}

\author{
Azad HamaAli Alshatteri $^{1 *}$ Abdulmutalib Rafat Sarhat ${ }^{1}$ Avesta M. Jaff $^{2}$ \\ ${ }^{1}$ Department of Chemistry, College of Education, University of Garmian. Kalar, Al-Sulaimaniyah, \\ Kurdistan Region, Iraq \\ ${ }^{2}$ Research Centre, University of Garmian. Kalar, Al-Sulaimaniyah, Kurdistan Region, Iraq \\ *Corresponding author. Email: Azadalshatteri@garmian.edu.krd
}

\section{Abstract}

This study was performed to evaluate the Siwran River water quality between Darbandikhan Downstream Dam and Kalar city for domestic and irrigation uses. Seven stations from different sites have been selected along the Sirwan River, and four replications from each station were taken. The parameters of water quality used in this work are (Turbidity, pH, Total hardness, Magnesium, Calcium, Sulphate, Nitrate, Chloride, Conductivity $\mu \mathrm{s} / \mathrm{cm}$, TDS). Data analysis shows that the water quality parameters of Sirwan River are not compatible with the drinking water standards especially the concentrations of Aluminum and Iron which show increasing levels than the maximum allowable levels for drinking water standards. In addition, to classifying water quality and evaluation its suitability for irrigation purposes, SAR, RSC, and ESP were calculated following standard equations and found experimentally as $0.5,1.7$, and 5.3 respectively. The results of the study revealed that the Sirwan River water should be used with good irrigation management techniques and soil salinity monitored by laboratory.

Keywords: Water Quality, Sirwan River, Aluminum concentrations, Sodium Adsorption Ratio (SAR), Residual Sodium Carbonate (RSC), Exchangeable Sodium Percentage (ESP).

\section{Introduction}

Water resources play an important role on population growth in any living area. With increasing inhabitants, water demand growths; meanwhile, the world is facing with severe water crisis. Rivers are most vital resources of fresh water in the world [1]. The water of rivers must be managed in an appropriate way particularly for those rivers pass 
through numerous countries [2]. Sirwan River is the source of lifeline to almost one million residents of Kurdistan Iraq. The cities along Rirwan River depend mostly on it for domestic, municipal, agriculture and other purposes. Water quality mainly depends on the physical, chemical and biological properties. These characteristics give an indicator on water use for a specific purpose.

Fresher water is important to human health, agriculture, and environments. The quality of water is a critical issue in the world. It is clear that the quantity of chemical composition in water is changed as a result of the changing the quantity of surface and ground water in a specific area [3]. For this reason, monitoring physiochemical properties of water are essential issue to deal with. The appropriate properties of water quality should include the measuring of $\mathrm{pH}$, temperature, dissolved oxygen, essential and toxic cation elements, anions, electrical conductivity, total dissolved solid, chemical oxygen demand, biochemical oxygen demand, total organic carbon, taste, color, and extra [4]. This study has been mainly conducted in order to measure and analyze the water quality parameters of Sirwan River such as electric conductivity EC, total dissolved solids TDS, sodium adsorption ratio SAR, magnesium hazard $\mathrm{MH}, \mathrm{pH}$, residual sodium carbonate RSC, that could potentially impact on the quality of water for drinking and irrigation crops.

\section{Methodology}

\subsection{Study Area}

The study area consists of seven sites along the river were selected between Darbandikhan downstream dam and Kalar District. Four replications sample from each site were selected. These sites are very important for drinking water as the study area was dense of the population along the banks of the river, as well as the presence of some industrial activities. Also, it includes a number of fallings the wastewater, which are distributed on both sides of the river. Therefore, dangers of various biological, chemical and physical pollutants could be existed, which can affect the quality of the river water as a source of water for processing drinking and irrigation water.

Figure (1) shows the location of sampling stations from downstream of Derbendixan River in Derbendixan area to Shexlenger village at down of Kalar district. Seven stations were selected along Sirwan River which starting from downstream of Darbandikhan Dam, Maydan, Bawanur, Isayi, Qulasutaw, Kalar, and Shekhlanger in south of the Kalar

City. Four replication water samples were collected from each of these stations during April 2018 in 1-L Poly ethylene bottles that are rinsed several times before filling. 


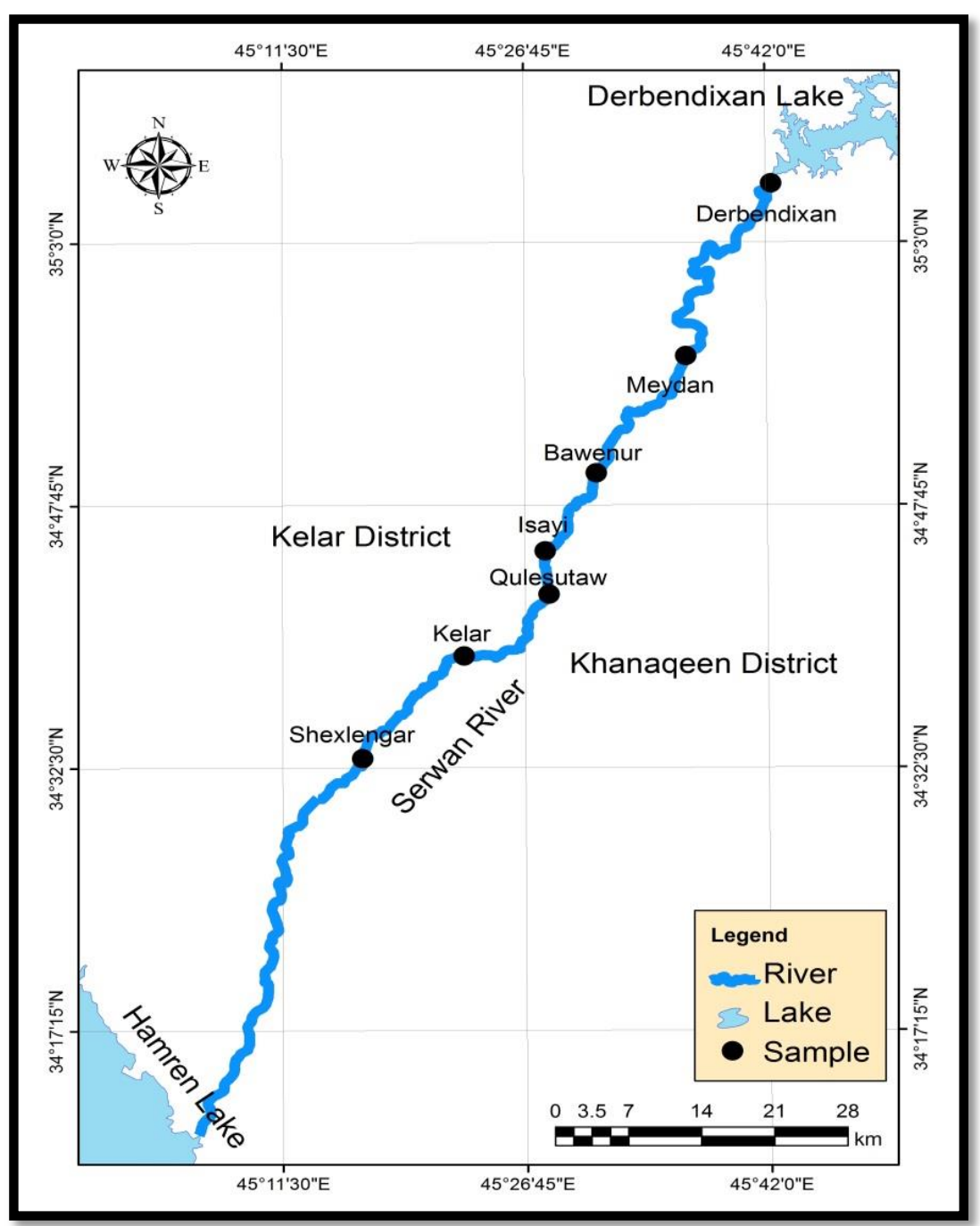

Figure 1: Location of the sampling stations.

\subsection{Physicochemical Study}

The samples were kept refrigerated and analyzed within 48 hours after collection in the laboratory of Chemistry Science Department in Garmian University. Various tests were conducted according to the Standard Methods for examination of water [5]. Some physicochemical parameters were study in site and composited at laboratory as required. The $\mathrm{pH}, \mathrm{EC}$ and DO were measured immediately in site by using a portable WTW conductometer and $\mathrm{pH}$ meter. TDS was measured using an HANNA instrument EC/TDS meter in a laboratory after the samples were arrived within 24 hours. $\left(\mathrm{SO}_{4}{ }^{2-}\right)$, chloride $\left(\mathrm{Cl}^{-}\right)$, and $\left(\mathrm{NO}_{3}^{-}\right)$ion concentrations were measured by means of SENTEK ion selective electrodes after 24 hours from sample collection. Some essential and toxic elements were analyzed using induced coupled plasma optical emission spectroscopy (ICPOES) 
(Spectro Arcos Germany). For analysis of water samples by ICPOES, the samples were acidified by $2 \% \mathrm{HNO}_{3}$, and then left for 24 hours before analysis. These parameters mainly consist of certain physical and chemical characteristics of water that are used in the evaluation of agricultural water quality.

\section{Results and Discussion}

Physicochemical properties were measured and their results can be seen in tables 1, 2, 3 and 4 respectively.

Table 1: Some results of the physicochemical for all samples

\begin{tabular}{|c|c|c|c|c|c|c|c|}
\hline Sample & $\begin{array}{c}\text { Turbidity } \\
(\mathbf{N U T})\end{array}$ & $\mathbf{p H}$ & $\begin{array}{c}\mathbf{E C} \\
(\boldsymbol{\mu S} / \mathbf{c m})\end{array}$ & $\begin{array}{c}\text { Total Hardness } \\
(\mathbf{m g} / \mathbf{l})\end{array}$ & $\begin{array}{c}\text { TDS } \\
(\mathbf{m g} / \mathbf{l})\end{array}$ & $\begin{array}{c}\text { D.O } \\
(\mathbf{m g} / \mathbf{l})\end{array}$ & $\begin{array}{c}\mathbf{N O}_{\mathbf{3}}^{-} \\
(\mathbf{m g} / \mathbf{l})\end{array}$ \\
\hline Darbandixan & 1.47 & 7.80 & 371 & 134.74 & 448.0 & 7.71 & 1.51 \\
\hline Maydan & $\underline{\mathbf{5 . 4 0}}$ & 7.60 & 455 & 137.02 & 456.0 & 7.73 & 4.56 \\
\hline Bawanur & 2.80 & 7.63 & 481 & 141.39 & 486.0 & 7.13 & 3.34 \\
\hline Isayi & 2.99 & 7.88 & 500 & 141.42 & $\underline{\mathbf{6 1 1 . 0}}$ & 7.92 & 2.62 \\
\hline Qulasutyaw & 2.88 & 7.60 & 485 & 140.52 & 485.0 & 7.45 & 3.66 \\
\hline Kalar & 1.63 & 7.76 & 468 & 135.98 & 463.0 & 7.99 & 2.96 \\
\hline Shexlangar & 1.72 & 7.35 & 788 & 143.82 & $\mathbf{6 5 7 . 0}$ & 6.70 & 3.37 \\
\hline Ave. & $\mathbf{2 . 7 0}$ & $\mathbf{7 . 6 6}$ & $\mathbf{5 0 6 . 8 6}$ & $\mathbf{1 3 9 . 2 7}$ & $\underline{\mathbf{5 1 5 . 1}}$ & $\mathbf{7 . 5 2}$ & $\mathbf{3 . 1 5}$ \\
\hline WHO & $\mathbf{5 . 0 0}$ & $\mathbf{6 . 5} \mathbf{- 8 . 5}$ & $\mathbf{4 0 0 - 8 0 0}$ & $\mathbf{5 0 0 . 0 0}$ & $\mathbf{5 0 0 . 0}$ & $\mathbf{5 . 0 0}$ & $\mathbf{4 5 . 0 0}$ \\
\hline
\end{tabular}

\section{1 pH of Water}

The $(\mathrm{pH})$ plays important roles in evaluating the acid-base balance of water. World Health Organization (WHO) has maximum acceptable limits of $\mathrm{pH}$ (6.5-8.5). The $\mathrm{pH}$ of the samples in the present study ranges (7.35-7.88) which is falling within the range of WHO limits. The overall results show that the Sirwan River water source is inside required and appropriate range.

\subsection{Electrical Conductivity (EC), Total Dissolved Solids (TDS), and Turbidity}

Unpolluted water is not a noble conductor of electric current. By increasing ion concentrations, electrical conductivity increases too [6]. Generally, (TDS) has the directly proportional with electrical conductivity. WHO has recommended standard tolerable limits for EC values that should not excessed (400) $\mu \mathrm{S} / \mathrm{cm}$ for drinking water [7]. The current study showed that the EC values were between $(371-788) \mu \mathrm{S} / \mathrm{cm}$. the results revealed that most of the results outside the WHO standard limits for drinking. However, for irrigation purpose the sample fall under medium category based on FAO standard.

Capacity of water is high to dissolve a numerous of inorganic and some organic minerals such as $\mathrm{Ca}^{+2}, \mathrm{~K}^{+}, \mathrm{Mg}^{+2}, \mathrm{CO}_{3}^{-2}, \mathrm{SO}_{4}^{-2}$, and $\mathrm{NO}_{3}^{-}$. These dissolved ions formed 
undesirable taste and color of water. Water with high TDS may affect persons suffering from heart and kidney diseases. WHO has a recommended maximum permissible limits of TDS which equals to (500) $\mathrm{mg} / \mathrm{L}$ [8]. The concentration of (TDS) in samples was indicated in the range of (448-657) $\mathrm{mg} / \mathrm{L}$ with an average of $(515) \mathrm{mg} / \mathrm{L}$. Therefore, it is out of the (WHO) standards limit for drinking purpose.

The values of turbidity in the river are ranged between (1.47-5.4) NTU, with the average value of (2.70) NTU. It can be considered as a safe limit [8]. Most of the samples do not exceed the turbidity limits (5 NTU). The permissible value for total hardness is (500) $\mathrm{mg} / \mathrm{l}$ according to the WHO [8].

\subsection{Dissolved oxygen (DO)}

In water body, oxygen is obtainable in a dissolved state. DO is the concentration of oxygen that is dissolved in water [9]. DO is measured as one of the most vital characteristic of aquaculture. It is desirable by fish to breathe and perform metabolic activities. Lower levels of (DO) are frequently connected to fish kill happenings. The deficiency of DO may be owing to temperature, breathing, photosynthesis, aeration, and organic waste [9]. DO in current study water ranged from (6.7-7.99) $\mathrm{mg} / \mathrm{L}$, with the mean value of (7.51) $\mathrm{mg} / \mathrm{L}$. DO value with more than $(5) \mathrm{mg} / \mathrm{L}$ is very important for fisheries life and production [10]. The results revealed that the DO is lower than desirable WHO limits in drinking water which equals to (8) $\mathrm{mg} / \mathrm{L}$.

\subsection{Nitrate $\mathrm{NO}_{3}^{-}$}

The allowable WHO maximum limits of nitrate is (45) $\mathrm{mg} / \mathrm{L}$ in drinking water [11]. In current investigation, it is clear that the $\mathrm{NO}_{3}{ }^{-}$concentration ranges from (1.51-4.56) $\mathrm{mg} / \mathrm{L}$ with the mean of $(3.15) \mathrm{mg} / \mathrm{L}$. These results show that amount of $\mathrm{NO}_{3}{ }^{-}$in the study sites are permissible.

\subsection{Cations $\left(\mathrm{Ca}^{+2}, \mathrm{Mg}^{+2}, \mathrm{Na}^{+}\right.$, and $\left.\mathrm{K}^{+}\right)$}

The concentrations of calcium were between (24.36-24.49) mg/l. All the samples were under acceptable and permissible limit. The concentrations of magnesium were between (17.95-20.17) $\mathrm{mg} / \mathrm{l}$. The water samples were within the permissible limits [12].

The samples analysis showed that the concentration of sodium vary between (12.3517.83) $\mathrm{mg} / \mathrm{l}$. These were observed to be within permissible limit. For drinking water the acceptable limit for $\mathrm{Na}$ is about (200) $\mathrm{mg} / \mathrm{l}$ [12]. On the other hand, potassium concentrations vary between $(2.17-21.13) \mathrm{mg} / \mathrm{l}$. Therefore, all samples had potassium concentration within the acceptable limit. 


\subsection{Anions $\left(\mathrm{Cl}^{-}, \mathrm{SO}_{4}{ }^{-2}\right.$, and $\left.\mathrm{NaHCO}_{3}{ }^{-}\right)$}

The present study indicated that the $\mathrm{Cl}^{-}$values were between $(33.67-231.01) \mathrm{mg} / \mathrm{L}$, and the mean is equals to $93.87 \mathrm{mg} / \mathrm{L}$. the results were lower than WHO standard limits [12].

$\mathrm{SO}_{4}^{-2}$ is mainly obtained from the dissolution of salts sulfuric acid and almost in all water bodies found in abundance. Extraordinary concentration of $\mathrm{SO}_{4}^{-2}$ is may be because of oxidation of pyrite and excavation drain [13]. By now not most important negative influence of $\mathrm{SO}_{4}^{-2}$ on human health is informed. In the current investigation, $\mathrm{SO}_{4}^{-2}$ ion concentration was ranged from $(135-165) \mathrm{mg} / \mathrm{L}$ with the average of (147) $\mathrm{mg} / \mathrm{L}$. The results revealed that the quantity of $\mathrm{SO}_{4}^{-2}$ in the study area is acceptable [11].

\subsection{Carbonate and Bicarbonate:}

They are existed in water because of some carbonate minerals present in water such as limestone, magnesite, and dolomite. This may influence $\mathrm{pH}$ values of water [14]. The concentrations of bicarbonate were between (258.64-378.2) $\mathrm{mg} / \mathrm{l}$ with an average of (293.6) $\mathrm{mg} / \mathrm{l}$, or (3.98-5.81) meq/l with an average of (4.51) meq/l. So, all samples were found to be within moderate limits [12].

Table 2: Cations and anions results of the study area

\begin{tabular}{|c|c|c|c|c|c|c|c|}
\hline Sample & $\mathbf{C a}^{+2}$ & $\mathbf{M g}^{+\mathbf{2}}$ & $\mathbf{~ a a}^{+}$ & $\mathbf{K}^{+}$ & $\mathbf{C l}^{-}$ & $\mathbf{S O}_{\mathbf{4}}^{-2}$ & $\mathbf{H C O}_{\mathbf{3}}$ \\
\hline Darbandixan & 24.46 & 17.95 & 12.35 & 2.17 & 35.10 & 144.0 & 268.4 \\
\hline Maydan & 24.49 & 18.49 & 12.39 & 2.17 & 119.70 & 136.0 & 258.6 \\
\hline Bawanur & 24.45 & 19.58 & 15.92 & 2.27 & 33.67 & 156.0 & 341.6 \\
\hline Isayi & 24.36 & 19.64 & 17.29 & 2.47 & 65.79 & 152.0 & 278.2 \\
\hline Qulasutyaw & 24.45 & 19.37 & 15.59 & 2.35 & 43.29 & 135.0 & 378.2 \\
\hline Kalar & 24.43 & 18.27 & 17.12 & 11.68 & 128.56 & 141.0 & 260.1 \\
\hline Shexlangar & 24.45 & 20.17 & 17.83 & 21.13 & 231.01 & 165.0 & 270.0 \\
\hline Ave. & $\mathbf{2 4 . 4 4}$ & $\mathbf{1 9 . 0 7}$ & $\mathbf{1 5 . 5 0}$ & $\mathbf{6 . 3 2}$ & $\mathbf{9 3 . 8 7}$ & $\mathbf{1 4 7 . 0}$ & $\mathbf{2 9 3 . 6}$ \\
\hline
\end{tabular}

Concentrations are expressed in $\mathrm{mg} / \mathrm{L}$.

\section{Water Quality Indexes}

\subsection{Sodium Adsorption Ratio SAR}

It is a measure of the suitability of water for agricultural irrigation, as calculated from the ratio of $\mathrm{Na}^{+}$to $\mathrm{Ca}^{+2}$ and $\mathrm{Mg}^{+2}$ by the following formula [15]:

$$
\mathrm{SAR}=\frac{\mathrm{Na}^{+}}{\sqrt{\left(\mathrm{Ca}^{2+}+\mathrm{Mg}^{2+} / 2\right.}}
$$


Excess sodium in water leads to produce undesirable effects of changing soil properties and reducing soil permeability [16]. All the samples in the study area have SAR values within the excellent class and acceptable for irrigation.

\subsection{Magnesium Hazard}

It can be calculated through using the flowing equation that was proposed by (Szabolcs and Darb, 1964) [17] :

$$
\mathrm{MH}(\mathrm{meq} / \mathrm{l})=\frac{\mathrm{Mg}^{2+}}{\left(\mathrm{Ca}^{2+}+\mathrm{Mg}^{2+}\right)} \quad \mathrm{x} 100
$$

The concentration of $\mathrm{Mg}^{+2}$ ion can play an important role in soil productivity. When the value of magnesium hazard is less than (50), the water will be considered as safe and suitable for irrigation. The results of the water samples of the study area observed that all the samples have $(\mathrm{MH})$ values greater than (50). Therefore, it cannot be used directly for irrigation without treatment or water management [17].

\subsection{Kelly's ratios KR}

It is the concentration of $\mathrm{Na}^{+}$against $\mathrm{Ca}^{+2}$ and $\mathrm{Mg}^{+2}$ [18]. Water for irrigation uses was classified based on Kelly's ratios. The Kelly's ratio values less than (1) are considered suitable for irrigation [18].

\subsection{Residual Sodium Carbonates RSC}

It represents the amount of sodium carbonate and sodium bicarbonate in water when the total levels of carbonate and bicarbonate exceed the total amount of $\mathrm{Ca}^{+2}$ and $\mathrm{Mg}^{+2}$ [19]. Residual carbonate values with less than (1.25) are considered as safe. However, RSC values of (1.25-2.50) are within the marginal range. Those types of water should be used with good irrigation management techniques and soil salinity monitored by laboratory analysis [20]. RSC values of (2.50) or more are considered as high making the water unsuitable for irrigation use. RSC is determined through [19]:

$$
\mathrm{RSC}=\left(\mathrm{CO}_{3}{ }^{2-}+\mathrm{HCO}_{3}{ }^{-}\right)-\left(\mathrm{Ca}^{2+}+\mathrm{Mg}^{2+}\right)
$$

All ion concentrations are expressed in meq/l. 
RSC values in the study area are ranges (1.2-3) with an average of (1.7). Therefore, most of the water samples are within the marginal range for irrigation except Qulasutaw station.

\subsection{Exchangeable Sodium Percentage (ESP)}

The desired value for ESP is (5) or less. However, values more than (5) mean increasing problems with soil infiltration and permeability, especially in clay soil. ESP value for irrigation water can be calculated from the following empirical relationship [20]:

$$
\mathrm{ESP}=100 *(-0.0126+0.01475 * \mathrm{SAR}) / 1+(-0.0126+0.01475 * \mathrm{SAR})
$$

Therefore, most of the water samples are unsuitable for irrigation regarding ESP except tow stations (Darbandikhan and Maydan) which they have ESP values of less than (5).

Table 3: Water quality index results of the study area

\begin{tabular}{|l|c|c|c|c|c|}
\hline \multicolumn{1}{|c|}{ Sample } & SAR & Mg\% & KR & RSC & ESP \\
\hline Darbandixan & 0.4 & $\underline{\mathbf{5 5 . 0}}$ & 0.2 & 1.4 & 3.8 \\
\hline Maydan & 0.4 & $\underline{\mathbf{5 5 . 7}}$ & 0.2 & 1.2 & 3.8 \\
\hline Bawanur & 0.5 & $\underline{\mathbf{5 7 . 2}}$ & 0.2 & $\underline{\mathbf{2 . 4}}$ & $\underline{\mathbf{5 . 5}}$ \\
\hline Isayi & 0.5 & $\underline{\mathbf{5 7 . 3}}$ & 0.3 & 1.4 & $\underline{\mathbf{6 . 2}}$ \\
\hline Qulasutyaw & 0.5 & $\underline{\mathbf{5 6 . 9}}$ & 0.2 & $\underline{\mathbf{3 . 0}}$ & $\underline{\mathbf{5 . 4}}$ \\
\hline Kalar & 0.5 & $\underline{\mathbf{5 5 . 5}}$ & 0.3 & 1.3 & $\underline{\mathbf{6 . 2}}$ \\
\hline Shexlangar & 0.5 & $\underline{\mathbf{5 7 . 9}}$ & 0.3 & 1.2 & $\underline{\mathbf{6 . 4}}$ \\
\hline \multicolumn{1}{|c|}{ Ave. } & $\mathbf{0 . 5}$ & $\mathbf{5 6 . 5}$ & $\mathbf{0 . 2}$ & $\mathbf{1 . 7}$ & $\mathbf{5 . 3}$ \\
\hline
\end{tabular}

\section{Heavy metals (total iron and Aluminum)}

Although total iron levels low in natural water; however, it can be present in various ionic, organic and mineral forms. The concentration of total iron varied from (0.0320.506) $\mathrm{mg} / \mathrm{L}$. Water samples at Bawanur, Qulasutaw, Kalar, and Shekhlanger showed high iron concentration than the prescribed limit by WHO which is $(0.3) \mathrm{mg} / \mathrm{L}$. On the other hand, the concentration of Aluminum in the analyzed samples was in the range of (0.093-2.411) $\mathrm{mg} / \mathrm{L}$ which also higher than the prescribed limit by WHO. Aluminum levels in drinking water vary according to the levels found in the source water and whether aluminum coagulants are used during water treatment [21]. The sludge of the water treatment units are directly disposed into the river. This ultimately leads to increase the level of Aluminum and Iron in the river.

Therefore, water from the river cannot be used directly for drinking purpose. This is due to the nature of raw materials used in the industry and municipal wastes. 
Table 4: The concentration of total Aluminum and Iron of study areas' samples

\begin{tabular}{|c|c|c|}
\hline Sample & T. Al & T. Fe \\
\hline Darbandixan & 0.093 & 0.032 \\
\hline Maydan & $\underline{\mathbf{0 . 4 9 1}}$ & 0.149 \\
\hline Bawanur & $\underline{\mathbf{2 . 4 1 1}}$ & $\underline{\mathbf{0 . 4 4 5}}$ \\
\hline Isayi & $\underline{\mathbf{0 . 4 2 3}}$ & 0.086 \\
\hline Qulasutyaw & $\underline{\mathbf{2 . 3 6 2}}$ & $\underline{\mathbf{0 . 4 0 3}}$ \\
\hline Kalar & $\underline{\mathbf{0 . 9 7 5}}$ & $\underline{\mathbf{0 . 5 0 6}}$ \\
\hline Shexlangar & $\underline{\mathbf{1 . 3 5 2}}$ & $\underline{\mathbf{0 . 4 7 9}}$ \\
\hline Ave. & 1.158 & 0.300 \\
\hline WHO & 0.200 & 0.300 \\
\hline
\end{tabular}

\section{Conclusion}

On the basic of results, it was concluded that physicochemical properties revealed that most of the parameter such as $\mathrm{pH}$, cations, and anions drop under the WHO permissible limits. However, there are some parameters like TDS, total Al, Fe fall outside of the permissible limits, and must be pretreatment before using for drinking. These parameters and. For irrigation purpose, data results show that the water of Sirwan River is medium salinity and may cause saline damages in the future. Also, some indexes including $\mathrm{Mg}$ hazards, ESP and RSC are with high values; therefore, water of the river should be used with good irrigation management techniques and soil salinity monitored by laboratory.

\section{References}

1. Abdelkader, T. A., and Mohamed H. E.: Hydrological And Environmental of Grand Ethiopian Renaissance Dam on the Nile River, IWTC18, 12-14, March, 2015

2. Latifah, A.M. and Les Met. An Ecological Evaluation Approach for Dam Project Development in Malaysia. Life Sci J 2014;11(7):225-237

3. Ling, T. Y., Soo, C. L., Heng, T. L. E., Nyanti, L., Sim, S. F., and Grinang, J.: Physicochemical Characteristics of River Water Down-stream of a Large Tropical Hydroelectric Dam, Journal of Chemistry, vol.(2016), 7 pages, http://dx.doi.org/10.1155/2016/7895234

4. Roman S., Lukasz W.: The impact of a reservoir on the physicochemical properties of water in a mountain river, Water and Environment Journal, 2013, 22-31 http://dx.doi.org/10.1111/wej.12059 
5. APHA, WWA \& WEF: "Standard Methods for Examination of Water and Wastewater," 21st Edition, pp. 333, American Public Health Association, Washington, D.C., 2005.

6. Sundaram, S. E. J., Elayaperumal, R., Kiruthika, M., Ramya, V. and Dharmalingam, P., "Effluents of Paper Mill: Physico-Chemical Properties of Water," International Journal of ChemTech Research, vol 6, pp. 3541-3545, 2014.

7. FAO, 1992, the use of saline waters for crop production. Irrigation and drainage paper 48. FAO, Rome. 1992.

8. WHO: Preventing Disease through Healthy Environments, Geneva, Switzerland, 2006, Accessed on 30 Oct. 2017, available at: http://www.who.int/quantifyingehimpacts/ publications/preventing disease /en /print.html.

9. Orebiyi, E. O., Awomeso, J. A., Idowu, O. A., Martins O., Oguntoke O., and Taiwo, A. M., "Assessment of Pollution Hazards of Shallow Well Water in Abeokuta and Environs,” Amer. J. Env. Sci., vol 6, pp. 50-56, 2010.

10.Bhatnagar, A. and Singh, G.: Culture fisheries in village ponds: a multi-location study in Haryana, India. Agriculture and Biology Journal of North America, issue: (1), No. (5), pp. 961-968. 2010.

11.WHO: Guidelines for drinking-water quality, 4th edn. Geneva, pp. 96, Switzerland, 2011.

12.WHO: Guidelines for drinking-water quality - 4th ed, pp. 851, World Health Organization 2011.

13. Yirdaw M., and Bamlaku A.: Drinking water quality assessment and its erects on residents health in Wando genet campus, Ethiopia, Meride and Ayenew Environ Syst Res (2016) 5:1, http://dx.doi.org/10.1186/s40068-016-0053-6

14.Natraj, V. M., Katya, D. and Gorntiwar, S: Study of groundwater contamination due to agricultural activity under Paravara laft bank canal, 2014, IJARIIE, ISSN(O)2395-4396.

15. Haritash, A. K., Kaushik, C.P. and kaushik, A: Suitability assessment of groundwater for drinking, irrigation and industrial use in some North Indian villages, 2008, Environ Monit Assess, 145: pp 397-406.

16.Biswas, S. N., Mohabey, H., Malik, M., L: Assessment of The Irrigation Water Quality Of River Ganga In Haridwar District, 2002, Asian J. Chem., pp 16.

17. Michael, A, M: Irrigation Theory and Practice, $2^{\text {nd }}$ edition, Vikas Publishing House, Pvt. Ltd., New Delhi, 2008. 
18.Kelly, W, P: Use of Saline Irrigation Water, Soil Sci., 1963, Vol.(95), Issue (4), pp.(35-39).

19.Rachel, P: Effects of water quality on soil, plants and irrigation equipment, Primary Industries and fisheries, April 2010.

20.Richards, L. A: Diagnosis and improvement of saline and alkali soils U.S. Salinity laboratory staff, USDA Handbook, 1954, pp 60-160.

21. World Health Organization (WHO): Guidelines for drinking-water qualityAluminum", $2^{\text {nd }}$ ed., 1998b, Addendum to Vol. 2. Health criteria and other supporting information, pp 66-269 World Health Organization, Geneva.

الخلاصة

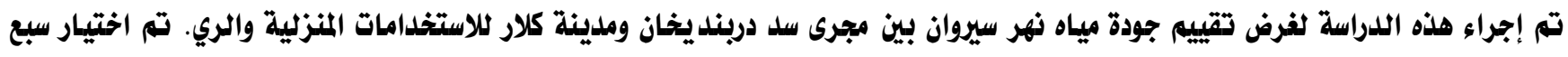

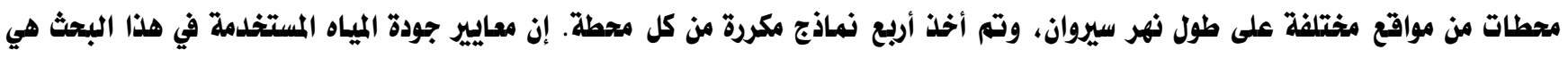

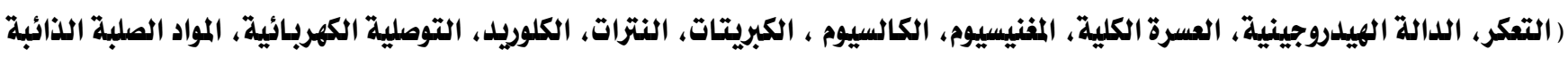

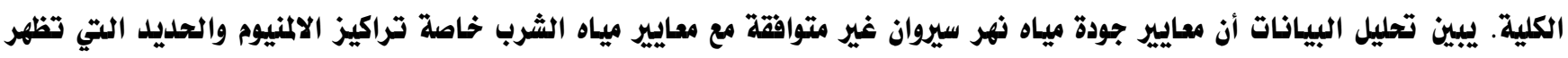

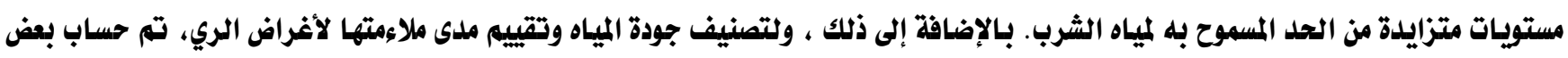

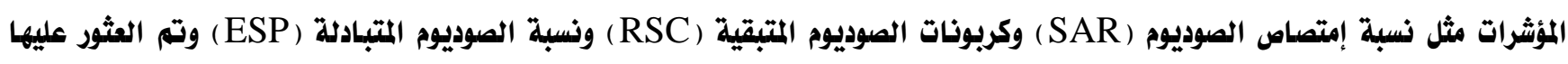

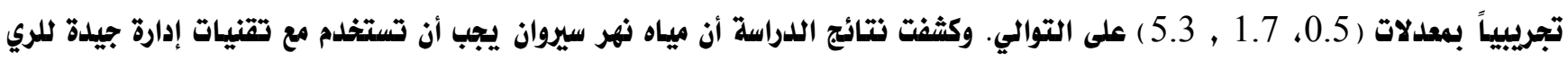
ومتابعة ملوحة التزبة.

الكلمات المفتاهية: جودة المياه، نهر سيروان، تركيز الالنيوم, نسبة امتزاز الصوديوم (SAR)، نسبة كاربونات الصوديوم المتبقية (RSC) ،

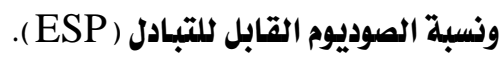

